\title{
Addressing the dual health epidemics of HIV and sexual abuse among children and adolescents in Kenya: uptake of HIV counseling and post- exposure prophylaxis
}

This article was published in the following Dove Press journal: Adolescent Health, Medicine and Therapeutics

\section{Carolyne Ajema' \\ Charity Mbugua ${ }^{2}$ \\ Peter Memiah ${ }^{3}$ \\ Camille Wood ${ }^{3}$ \\ Courtney Cook ${ }^{4}$ \\ Ronald Kotut ${ }^{2}$ \\ Lina Digolo'}

'Research and Strategic Information Department, LVCT Health, Nairobi, Kenya; ${ }^{2}$ osst Rape Care Department, LVCT Health, Nairobi, Kenya;

${ }^{3}$ Department of Public Health, University of West Florida, University Parkway, Pensacola, FL, USA; ${ }^{4}$ Biology Department, University of West Florida, University Parkway, Pensacola, FL, USA
Correspondence: Carolyne Ajema LVCT Health, PO Box 19385-00202, $\mathrm{KNH}$, Nairobi, Kenya

Tel +254722 203610

Fax +254202633203

Email carol.ajema@lvcthealth.org
Purpose: Child sexual abuse and HIV are key health challenges in Kenya. In 2015, LVCT Health conducted a study aimed at assessing the quality of HIV-related services offered to child survivors of sexual violence in public health facilities.

Materials and methods: A qualitative data collection approach was utilized. Qualitative data were collected through in-depth interviews with 31 providers. Quantitative methods included a retrospective review of 164 records of child survivors of rape who had accessed services 6 months prior to the commencement of the study. SPSS Version 22 was used in the descriptive analysis of the medical records. Client exit interviews and observation data were analyzed using MS Excel. In-depth interviews were analyzed using a thematic analytical approach.

Results: Twenty-seven percent $(n=164)$ survivors were documented to have received the first dose of postexposure prophylaxis (PEP). Providers did not conduct HIV pre- and posttest counseling for the survivors. There were no longitudinal follow-up mechanisms to ensure child survivors initiated on PEP adhered to the treatment plan. Less than $30 \%$ of survivors returned to the facility for PEP adherence counseling and follow-up HIV testing. Twenty providers cited capacity gaps in undertaking HIV risk assessment for child survivors. Limited availability of PEP is a barrier to HIV prevention, as most departments only offer services between 8 am and $5 \mathrm{pm}$. HIV tests were only available on weekdays before $5 \mathrm{pm}$. PEP being out of stock remains a barrier to HIV prevention.

Conclusion: Existing post-rape care services are not adequately structured to facilitate delivery of quality HIV-related services to child survivors. Health provider capacity in the management of children remains weak due to lack of skill-based training on the dynamics of responding to the needs of child survivors. There is a need for standard operating procedures and training modules on the prevention of HIV in the context of child sexual abuse.

Keywords: child sexual abuse, post-rape care, sexual violence, HIV, PEP, children in Kenya

\section{Background}

Child sexual abuse and HIV have been increasingly recognized as public health problems. ${ }^{1}$ The World Report on Violence against Children in 2002 indicated that $~ 150$ million girls and 73 million boys experienced sexual abuse globally. ${ }^{2,3}$ While the incidence of HIV acquisition among children through sexual abuse remains unknown, evidence exists to show rising HIV prevalence among children and adolescents. ${ }^{4,5}$ Despite the dearth of data on possible HIV infections in the context of sexual violence, there is little evidence demonstrating that sexual abuse increases vulnerability to HIV infection 
among children..$^{6-9}$ The increased risk of HIV seroconversion following sexual abuse is attributed to the increased physical trauma, especially in children.

In Kenya, the Violence against Children Survey found that $32 \%$ of females and $18 \%$ of males had experienced sexual violence before they reached 18 years of age. ${ }^{10}$ Exposure to child sexual abuse increases the likelihood of high-risk behaviors including substance abuse, low self-esteem, having multiple sexual partners, and engaging in unprotected sexual intercourse. ${ }^{11}$ This increase in high-risk behavior enhances the likelihood of survivors of child sexual abuse engaging in behaviors that also propagate their risk of HIV infection into childhood and/or adulthood. ${ }^{12-15}$ A study conducted in New Zealand among 520 females who were $<18$ years of age revealed that $59 \%$ of those who had experienced child sexual abuse had more than five sexual partners in comparison to $13 \%$ who had no prior incidence. ${ }^{16}$

Child survivors experience an array of psychological and emotional disorders. These include posttraumatic stress disorder, suicidal ideation, substance use, anxiety, depression, among others. ${ }^{17,18}$ Adverse mental health is not only an outcome of sexual violence, but also predicts sexual and reproductive health outcomes and HIV risk behavior. Mental distress has been associated with nonadherence to HIV treatment. ${ }^{19,20}$ Survivors of sexual abuse may also experience avoidance, and/or have poorer self-efficacy, which may affect their adherence levels to medication, including HIV postexposure prophylaxis (PEP). ${ }^{21,22}$ There is, however, scarcity of evidence in Kenya on how posttraumatic stress disorder predicts adherence or nonadherence to HIV treatment, more so in the context of child sexual abuse.

\section{Services available to address sexual abuse in Kenyan public health facilities}

Public health facilities in Kenya are often the first points of help sought out by survivors of child sexual abuse. An integrated service delivery is utilized by these facilities, where survivors of sexual abuse receive services within the general health system along with the general public who also access care at these facilities. The post-rape care (PRC) services are aimed at reducing physical and psychological consequences of sexual abuse. Services provided to survivors include forensic examination, emergency contraception, PEP for HIV prevention, management of sexually transmitted infections, and psychological support and counseling. Immediate management of survivors for HIV care is undertaken within the health facilities, comprehensive care clinics (CCC). Survivors who report within 72 hours are offered an HIV test and counseling, the first dose of PEP, and other prophylactic treatment. Those who present after 72 hours are referred for psychosocial support and any additional medical management that may be required. Table 1 outlines the service package offered to survivors in accordance with the Kenyan Ministry of Health guidelines on the management of survivors of sexual abuse.

The HIV-related counseling services offered to child survivors mainly address the HIV pre- and posttest, drug adherence, and enrollment into HIV care for those who test positive at baseline. HIV tests are undertaken between days 1 and 3 after the sexual abuse, and a follow-up test is administered 3 months later. The HIV pre- and posttest counseling entails providers 1) offering basic HIV information for survivors; 2)

Table I Services for survivors of sexual violence

\begin{tabular}{|c|c|}
\hline $\begin{array}{l}\text { Visit } \\
\text { number }\end{array}$ & Recommended services \\
\hline $\begin{array}{l}\text { First visit at } \\
\text { Day I-3 }\end{array}$ & $\begin{array}{l}\text { - Obtain sexual assault history } \\
\text { - If eligible, provide prophylaxis (PEP stat dose, ECP, } \\
\text { and STI drugs) } \\
\text { - Undertake physical examination } \\
\text { - Undertake forensic evidence collection and analysis } \\
\text { - Undertake laboratory investigations } \\
\text { - Refer for psychosocial assessment and support } \\
\text { - Document history obtained, and treatment } \\
\text { - } \text { - Schevided, on PRC form } \\
\text { - Refer to police (if willing) }\end{array}$ \\
\hline $\begin{array}{l}\text { Second visit at } \\
2 \text { weeks }\end{array}$ & $\begin{array}{l}\text { - Provide PEP refill } \\
\text { - Assess adherence to treatments previously given } \\
\text { - Evaluate for STIs and treat if necessary } \\
\text { - Evaluate mental and emotional status; treat or refer } \\
\text { as needed } \\
\text { - Provide adherence and trauma counseling to } \\
\text { survivor and family } \\
\text { - Assess uptake of external referrals given in the first } \\
\text { visit }\end{array}$ \\
\hline Third visit at & - Check for PEP completion \\
\hline & $\begin{array}{l}\text { - Repeat pregnancy test and refer for care if } \\
\text { necessary } \\
\text { - Do follow-up vaccinations } \\
\text { - Evaluate for STIs and treat if necessary } \\
\text { - Evaluate mental and emotional status; treat or refer } \\
\text { as needed } \\
\text { - Provide trauma counseling }\end{array}$ \\
\hline Fourth visit at & - Evaluate for STls and treat if necessary \\
\hline 6 weeks & $\begin{array}{l}\text { - Evaluate mental and emotional status; refer or treat } \\
\text { as needed } \\
\text { - Provide trauma counseling }\end{array}$ \\
\hline Fifth visit at & - Retest for HIV and refer for care if necessary \\
\hline 3 months & $\begin{array}{l}\text { - Evaluate for STIs and treat if necessary } \\
\text { - Evaluate mental and emotional status; refer or treat } \\
\text { as needed } \\
\text { - Provide trauma counseling }\end{array}$ \\
\hline
\end{tabular}

Abbreviations: ECP, emergency contraceptive pills; PEP, postexposure prophylaxis; PRC, post-rape care; STIs, sexually transmitted infections. 
explaining the benefits of HIV testing; 3 ) undertaking a risk assessment and risk reduction plan; 4) discussing the possible implications of the HIV test results; 5) discussing the window period (up to 6 weeks); 6) reviewing the survivor's and/or guardian's understanding and readiness for the HIV test; and 7) conducting the HIV test itself. ${ }^{23}$ Despite the increased risks associated with HIV and child sexual abuse, both age and socioeconomic status limit access to both information and services in many settings for children.

This study was undertaken in 2015 by LVCT Health, a Kenyan nongovernmental organization. The primary focus was to assess the quality and comprehensiveness of PRC services provided to child survivors of sexual violence in Kenyan public health facilities. According to the World Health Organization, components of quality care include skilled health care providers, availability, and quality of supplies and equipment, and an environment that promotes privacy and confidentiality. In Kenya, quality care refers to the provision of services to child survivors of sexual abuse in accordance with the national guidelines on the management of sexual violence. This paper focuses on the HIV component of services received by child survivors of sexual abuse, namely PEP and HIV-related counseling services, and the perspectives of health providers in providing these services.

\section{Materials and methods}

\section{Sample selection}

Two county-level hospitals offering PRC services for at least 5 years were selected from different geographic locations.
Health care providers from the two county-level hospitals were selected using purposive sampling to ensure inclusion of those whose daily responsibilities included the provision of PRC services in accordance with the national guidelines on the management of sexual violence in Kenya. The health care providers were selected by taking into consideration their experience in providing PRC services and willingness to participate in the study. The selection was from the following service delivery areas: outpatient departments, CCC, wards, pharmacy, laboratory, and HIV testing centers. A total of 31 health care providers were interviewed, including medical officers (2), clinical officers (5), laboratory technologists (5), nurses (10), counselors (1), social workers (1), and pharmacists (6). Sixty-one percent of those interviewed were female and a majority $(48 \%, \mathrm{n}=31)$ had been in service for $1-5$ years.

The medical records abstraction constituted a review of all documentation done by service providers for survivors of sexual violence in the course of patient examination and treatment. These included PRC form, PRC register, departmental register maintained with the laboratory, counseling, and pharmacy for survivors of sexual abuse. A total of 164 survivor entries for survivors under 18 years of age who accessed PRC services 6 months prior to the commencement of the study were abstracted (Table 2). The survivor records were identified by the facility PRC in charge.

\section{Study instruments}

Qualitative data collection was conducted through the use of a key informant guide to help explore the following aspects of

Table 2 Survivor demographics

\begin{tabular}{|c|c|c|c|c|c|c|c|c|}
\hline & & \multicolumn{6}{|c|}{ Health facility name } & \multirow[t]{3}{*}{ P-value } \\
\hline & & \multicolumn{2}{|c|}{ Nyeri PGH } & \multicolumn{2}{|c|}{ Naivasha hospital } & \multicolumn{2}{|l|}{ Total } & \\
\hline & & Count & $\%$ & Count & $\%$ & Count & $\%$ & \\
\hline \multirow[t]{2}{*}{ Gender } & Male & 5 & 9 & 7 & II & 12 & 10 & 0.672 \\
\hline & Female & 51 & 91 & 55 & 88.7 & 106 & 89.8 & 0.004 \\
\hline \multirow[t]{4}{*}{ Age, years } & $1-4$ & 6 & 11 & I & 1.8 & 7 & 6.1 & \\
\hline & $5-9$ & 5 & 9 & 19 & 33.3 & 24 & 21.1 & \\
\hline & $10-14$ & 23 & 40 & 16 & 28.1 & 39 & 34.2 & \\
\hline & $15-19$ & 23 & 40 & 21 & 36.8 & 44 & 38.6 & \\
\hline Median age (IQR) & $14(10-16)$ & & & $13(8-16)$ & & $14(9-16)$ & & \\
\hline \multirow[t]{4}{*}{ Number of perpetrators } & I & 49 & 88 & 59 & 93.7 & 108 & 90.8 & 0.150 \\
\hline & 2 & 7 & 13 & 2 & 3.2 & 9 & 7.6 & \\
\hline & 3 & 0 & 0 & $\mathrm{I}$ & 1.6 & 1 & 0.8 & \\
\hline & II & 0 & 0 & I & 1.6 & I & 0.8 & \\
\hline \multirow[t]{3}{*}{ Gender of the perpetrator } & Male & 40 & 95 & 64 & 98.5 & 104 & 97.2 & 0.877 \\
\hline & Female & I & 2 & I & I.5 & 2 & 1.9 & \\
\hline & Both & I & 2 & 0 & 0.0 & I & 0.9 & \\
\hline \multirow[t]{2}{*}{ Type of assault recorded } & Vaginal & 55 & 94.8 & 56 & 90.3 & I I I & 92.5 & 0.349 \\
\hline & Anal & 3 & 5.2 & 6 & 9.7 & 9 & 7.5 & \\
\hline Known relationship with & Known & 47 & 88.7 & 59 & 88.1 & 106 & 88.3 & \\
\hline perpetrator & Unknown & 6 & 11.3 & 8 & 11.9 & 14 & II.7 & 0.916 \\
\hline
\end{tabular}

Abbreviation: IQR, interquartile range. 
PRC service provision: knowledge of the available guidelines on management of survivors of sexual abuse, provider perceptions of and experiences with regard to provision of counseling services to child and adolescent survivors of sexual abuse, and barriers to providing services. Data obtained through the interviews were triangulated with service statistics. Informed consent was obtained from each respondent before in-depth interviews were conducted, and the participants were asked to sign an individual consent form as an indication of agreement to participate in the study. Permission was sought from all respondents to have the interviews audio-recorded. The interviews and data abstraction were undertaken by a team of four research officers with vast training in undertaking similar studies. An MS-Word data abstraction tool was utilized by the research officers to capture this data. Data collection was undertaken over a period of 1 month. All of the interview transcripts and PRC records were anonymized through a coding system and stored in locked cabinets.

\section{Data analysis}

The in-depth interviews were managed using a Word processor and analyzed using NVIVO 10. A thematic framework approach was used to analyze the data. A coding framework was developed as informed by the emerging themes. Health facility data for survivors of sexual violence was entered and descriptive analysis undertaken using SPSS 22.

\section{Ethical considerations}

Ethical approval was obtained from both the Population Council Institutional Review Board and the African Medical Research Foundation Research Ethics Committee. In order to retrieve medical records maintained for survivors of sexual violence, permission was obtained from the facility Medical Superintendent. Written informed consent was obtained from all the health providers who participated in the study.

\section{Results}

Health care providers were asked questions regarding the type of HIV service offered to clients with a focus on HIV testing, counseling and PEP, follow-up mechanisms in place to ensure uptake of HIV adherence counseling sessions, and barriers they experience in the provision of HIV-related services. Results are presented under the following areas: 1) survivors accessing health services; 2) time of presentation after the incident; 3 ) provision of PEP; 4) provision of HIV counseling and testing; 5) uptake of follow-up HIV PEP adherence counseling sessions; and 6) barriers to HIV service provision.

\section{Survivors accessing health services}

One hundred and sixty-four child and adolescent survivors of sexual abuse accessed services in the two facilities over a 6-month period prior to the commencement of the study. Only $78 \%(n=128)$ of the survivors had their gender documented on the health facility records reviewed under this study. The vast majority of survivors $(93 \%)$ were female. The age of the survivors ranged from 2 to 19 years, as indicated in $90 \%$ $(n=136)$ of the PRC forms. The largest proportion consisted of 16-year-olds (15\%) followed by 17-year-olds (11\%), with a median age of 14 years (Table 2).

\section{Disclosure of perpetrator and time of presentation after the incident}

More than $38 \%(n=164)$ of child survivors of sexual violence did not present to the health facility for medical attention within the 72-hour period stipulated in the national guidelines on the management of survivors of sexual violence in order to be eligible for PEP. It is also worth noting that $42 \%$ of victims who knew the perpetrator did not report to the health facility within the 72-hour period (Table 3 ).

Health service providers stated that the age of child survivors who report at the facility and their relationship with the perpetrator may also hinder disclosure of the assault as contributing factors to the delayed reporting for services:

\begin{abstract}
Mostly survivors are young children [...]. Rarely do we find children who are above like 10 years, we handle those small ones who actually sometimes they even do not know what happened to them. [Nurse - Gynecologic Ward]

The children who come here with the sexual abuse are as young. Some are months old, but most of them are aged between four and eighteen years. Most of them are sexually abused by the neighbors and even of late they are being abused by their fathers. [Nurse - CCC]
\end{abstract}

\section{Provision of PEP}

Approximately $27 \%(n=164)$ of the survivors were documented to have received the first dose of PEP. Only 5\% of those who tested HIV negative at baseline $(n=39)$ were documented to have received the first dose of PEP.

Table 3 Time within which survivors presented for health care

\begin{tabular}{llll}
\hline Time of survivors' & \multicolumn{2}{l}{ Knowledge of perpetrator } & Total, n (\%) \\
\cline { 2 - 3 } presentation & Known (\%) & Unknown (\%) & \\
\hline$<72$ hours & $5 \mathrm{I}(58.0)$ & $\mathrm{II}(91.7)$ & $62(62.0)$ \\
$>72$ hours & $37(42.0)$ & $\mathrm{I}(8.3)$ & $38(38.0)$ \\
Total & $88(100.0)$ & $12(100.0)$ & $100(100.0)$ \\
\hline
\end{tabular}


Most of the providers reported that the initial dose of PEP is given to all survivors who present within 72 hours before they undergo HIV testing.

You give PEP whether they are tested [for HIV] or not, you give a standard dose of PEP then they are tested later. [Nurse - Casualty Department]

They [survivors] are given PEP immediately and then if she is positive you continue counseling, but start her on HIV treatment if she [is] not on ARVs [antiretrovirals]. [Nurse - Mother and Child Health Clinic]

However, the majority $(n=17)$ of health care providers cited variations on how the follow-up doses of PEP should be administered to those who tested HIV negative.

They [survivors] are given a weekly program of the [...] the drugs until they continue 28 days of the PEP. But they are reviewed weekly. [Nurse - Casualty Department]

They [survivors] are never dispensed [given] the whole dose. They are given PEP for 1 week. And when they come for the next counseling session, they pick another dose for the next several days. [Nurse - Gynecological ward]

We give a dose of 14 days and then we tell them to come for the rest of drugs after the 14 day period. [Pharmacist]

Others stated that due to their uncertainty of whether the survivor will return to the facility for follow-up, they dispense the full 28-day PEP dose during the first visit.

If its weekend we give them for 3 days and then on Monday they come for the full dose. I'm not sure how many have been returning. That's another challenge. [Medical Officer

- Pediatric Ward]

You find that most of them do not come back for the second dose. [Pharmacist]

Another provider reported it was challenging to know which of the cases that present for PEP were as a result of coerced sex, as some adolescent survivors came to the facility requesting PEP although they engaged in consensual sex.

I have come across a few [survivors] who are from secondary schools, but you find that it is not actually rape, but rather a case of them staying [having an intimate relationship] with a boyfriend. [...] [Clinical Officer-Outpatient Department]

\section{Provision of HIV counseling and testing}

According to the national guidelines on the management of survivors of sexual violence, the HIV test must be conducted in the laboratory. While the providers were aware of this provision within the guidelines, few of them cited this practice as a hindrance to the provision of pre- and posttest HIV counseling to child survivors of sexual abuse.

Counseling is not done exclusively because when they go to the laboratory, they are not counseled [...]. When the results come they are given PEP and they are just told about the side effects of PEP. They are not counseled before testing and after testing. [Clinical Officer-Outpatient Department]

We don't do counseling, as it is done outside [the laboratory] by the nurses. [Laboratory Technician]

According to the providers, HIV counseling and testing ought to be carried out simultaneously:

It can be easier if counseling is done concurrently with the testing. Instead of doing it in the laboratory whereby counseling is never done. So even after getting the HIV result, it is positive, what next? They are just given results, they are not counseled. [Nurse - CCC]

In addition, the majority ( $\mathrm{n}=21$ ) of the providers reported not having adequate counseling skills when it comes to child and adolescent survivors of sexual abuse.

Children are not small adults so you should handle them with all their special needs. Counseling them is hard. We should be trained on how to handle children. [Clinical Officer Gender-Based Violence Recovery Center]

Some of these children are quite young and handling them becomes hard some are agitated [...] Counseling is quite hard. But we try because we want to help the client. [Nurse - Gynecological ward]

Some health care providers cited challenges on how to counsel to children, which is the reason why they instead choose to focus on the caregivers:

We should have people trained on children counseling. Because it is quite different from the [...] from the adults. Like when we get these small children from the ages of 1 to 6 years, it is quite a challenge. So we end up counseling the parents and not the kids. [Nurse - CCC]

If the child needed counseling, what we do is call the relevant counselor to counsel the parents, the guardians of the child. [Nurse - Pediatric Ward]

\section{Uptake of follow-up HIV PEP adherence counseling sessions}

Some of the providers also cited lack of follow-up mechanisms for survivors after the initiation of care and treatment to ensure full uptake of PEP in addition to having the routine liver function tests performed. 
Some of them [survivors] will take the PEP because we are with them in the ward, but when they go home and experience side effects some are not able to continue taking PEP. You also do not know whether the survivor was in the incubation period so by the end of the day you get a client turning HIV positive which could have been prevented. Even the guardian of the child should make sure the patient is taking the drug and taking it at the right time before they come back for a repeat test. [Nurse - Gynecological Ward]

Some providers $(n=5)$ mentioned that the uptake of counseling and HIV-related services by children and adolescents is largely dependent on their adult caregivers, as they are required to provide consent before the child can be offered the services needed.

[...] sometimes a child may be assaulted and then is brought to the hospital by someone else, other than the mother. So in such cases, you have to contact the relatives to come and give consent. Of course, a teacher or any other person cannot give consent unless you involve the parent. [Nurse-Outpatient Department]

This requirement of having a caregiver give consent is challenging due to nondisclosure of the abuse and/or the HIV results. In some instances, the caregiver might be the perpetrator of the abuse.

You need to get the consent of the parent. You also have to make this child understand, and sometimes it is not very easy as they [survivors] will also require somebody they trust to support them. And other times they are brought in by even the perpetrators themselves. [Nurse - Youth Friendly Clinic]

Psychosocial support sometimes has problems because you see this child is not the one to decide for herself, it is the guardian who will decide on what to do and the way forward. [Adherence Counselor - CCC]
The record review revealed $<30 \%$ uptake of follow-up of HIV PEP adherence counseling sessions and repeat HIV testing as illustrated in Figure 1.

\section{Barriers to HIV service provision}

Health care providers' negative experiences in handling child and adolescent survivors were considered to be barriers to providing HIV-related services, including PEP and counseling. The barriers in this study were categorized into health provider- and service delivery-related barriers.

\section{Health provider-related barriers}

Limited skills, knowledge, and training opportunities were cited as barriers to providers from both facilities. The majority $(n=20)$ of the providers expressed difficulty in engaging with child and adolescent survivors, including exploring their HIV-related risks, explaining the importance of adherence to PEP, and undertaking counseling in a manner that is well understood by the survivors.

Provider attitude also emerged as a barrier to service delivery.

Survivors at times complain about the attitude of clinicians.

They [survivors] feel that they are not handled well, they need clinicians to change their attitude when handling them. They also say a lot of time is taken before they are attended to. One [survivor] told me [provider] that she came [to the hospital] empty and she left empty without someone to talk to and to express herself. [Clinical officer-Outpatient Department]

Few providers reported having undergone training on management of child survivors, resulting in the prescription of the wrong medication.

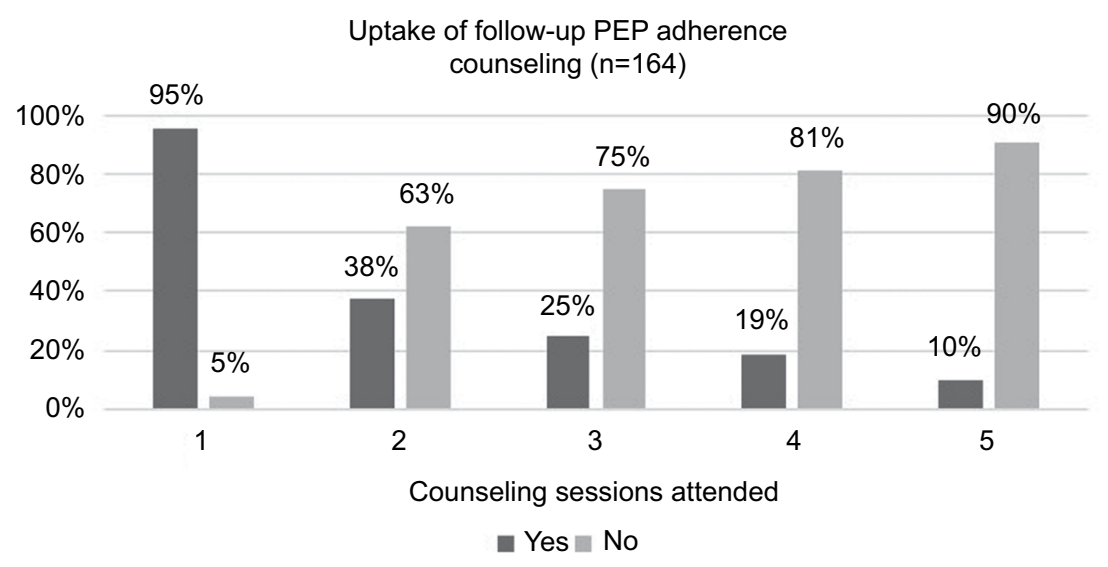

Figure I Survivors documented to have received follow-up counseling. Abbreviation: PEP, post-exposure prophylaxis. 
Providers should be taught in whichever areas they are supposed to concentrate on when attending to survivors, the test they are supposed to perform, counseling which is also very important, and mostly on ARVs provision. Because we have had a situation whereby these children are seen in the outpatient and a wrong prescription of ARVs is given. [Nurse - CCC]

\section{Service delivery-related barriers}

Inadequate supply of PEP, high workloads, inadequate utilization of the data capture tools, limited staffing, and use of multiple rooms to offer the HIV package of care were barriers mentioned by the majority of the providers at the two facilities. The long period of waiting before survivors were treated was also cited as a barrier.

Most of the times, we are not able to do an efficient followup, because of the workload. [Pharmacist]

We need more counselors so that immediately these victims come they don't wait for long or they are not booked. The counselors are few and are not able to handle all the cases. Some clients are even made to come to the facility the following day, in instances where the counselor is busy or not available. [Nurse - Gender Recovery ward]

We need a room whereby when this person [survivor] comes you are able to [...] take the history, do your examinations, fill the forms, give the drugs that they need, and also do the counseling, all at one point [department], instead of sending them from one department to another. [Nurse - Pediatric ward]

PEP being out of stock remains a barrier to HIV prevention.

At times we do not have specific pediatric allocations for these survivors due to stock-outs. [Pharmacist]

Some of the medication, including PEP is not always there in the pharmacy. [Clinical Officer - Outpatient Department]

Lack of follow-up mechanisms to ensure survivors' adherence to the HIV package of care was also reported since not all survivors return to the facility to collect the full dose of PEP. Providers also reported a lack of mechanisms to ensure that these survivors return to collect the full dose of PEP.

Providers reported that laboratory services were offered within a specific time frame, and HIV tests were only available on weekdays before $5 \mathrm{pm}$.

Testing is done during the day but at night they are requested to come for testing the following day. [Laboratory Technician]
Patients who come from Friday evening have to wait till

Monday to be tested for HIV. [Nurse - CCC]

It was noted that in some instances, child survivors were brought to the hospitals by strangers who do not have any legal mandate to give parental consent before any counseling or testing is undertaken. In such instances, there is a high likelihood of the survivor missing out on the full dose of PEP and/or counseling.

Of course a teacher or any other person cannot give consent unless you involve the parent. And if the parent is not there, we have to involve the police, the children officer so that we can go ahead with it [giving PEP]. [Nurse - Outpatient Department]

\section{Discussion}

The high proportion of cases of child sexual abuse presenting in health facilities has a significant impact on HIV programming and scale-up of PRC services in Kenya. The absence of clear guidelines in addressing HIV prevention and related counseling in the context of child sexual abuse remains a challenge, despite survivors presenting within the 72-hour period. Evidence demonstrates that PEP is most effective when administered within 72 hours after sexual or nonoccupational exposure. ${ }^{24-26}$

The majority of providers $(n=26)$ interviewed in this study cited challenges in the provision of HIV-related counseling to child survivors of sexual abuse, irrespective of having received general training on PRC service delivery. In addition, only two providers were found to have undergone comprehensive training on medical management of child survivors of sexual abuse. Although providers in this study affirmed the need for all survivors who present within 72 hours and are tested HIV negative to be given PEP, their personal beliefs on whether the children had engaged in consensual sex, at times, hindered HIV service delivery. This reluctance emerged from cases where the child survivors acknowledged having engaged in consensual sex, despite a differing opinion from their caregivers who reported their children as having been abused. The lack of guidance on the age at which survivors under 18 years of age can seek PRC services without being accompanied by a legal guardian poses a challenge in that the providers experience a dilemma on whose report to rely on in delivering HIV-related services the child or the caregiver. The lack of clear guidelines on how to address PEP issuance in the context of ongoing sexual exposure to HIV among survivors of sexual abuse, including children and adolescents, remains a challenge globally. ${ }^{27}$ 
The national guidelines on the management of survivors of sexual violence in Kenya stipulate that child survivors should be offered pediatric dosages of PEP. ${ }^{23}$ However, there are challenges in ensuring an adequate supply of PEP in public health facilities, as well as in administering PEP to children using dosages prepared for adults. Policy guidelines on sexual violence management targeting children remain unclear as to what measures are necessary to ensure that children who experience sexual abuse are adequately screened, initiated into PEP treatment, receive the complete PEP regimen, and receive HIV-related counseling.

PEP, in the context of sexual abuse, should be administered over a 28 -day period. ${ }^{26,28}$ It has been demonstrated that adherence to a full 28-day course of PEP is critical toward the prevention of HIV. ${ }^{29,30}$ Consequently, follow-up of survivors initiated on PEP is crucial to facilitate monitoring of drug toxicity, enablement of provider-offered counseling that is essential for PEP adherence, and in addressing any resulting mental distress. ${ }^{31}$ In the context of child survivors, it is recommended that clinicians undertake an initial follow-up within the first 3 days to assess adherence, evaluate any symptoms of toxicity, assess the mental status of both child and caregiver, and provide any required referrals. According to the Kenyan national guidelines on the management of sexual violence, laboratory testing for drug toxicity should be performed at baseline, 2 weeks (optional), and 4 weeks after starting therapy. ${ }^{23}$ However, in this study, providers cited lack of mechanisms to enable them to follow-up with child survivors to monitor their adherence to PEP and intervene in case of adverse side effects. Providers, therefore, rely on client self-discipline in adherence to the treatment plan. Child survivors' reliance on their caregivers to facilitate their access to services remains problematic due to transport barriers that may hinder them from visiting the hospital for follow-up care. This study could not establish a level of adherence to PEP due to poor documentation of survivors accessing PRC services.

The results presented highlight the need for measures to ensure availability of HIV-related services for child survivors of sexual violence. The measure would include training providers on how to better offer the services and implementing mechanisms to facilitate 24-hour delivery of services to child survivors of sexual abuse.

\section{Conclusion}

Provision of HIV-related services in the context of PRC is feasible. However, this study showed significant gaps in accessibility of child survivors to PRC services. While providers placed emphasis on the provision of the first dose of PEP, increased emphasis should also be attached to routine follow-up in order to ensure adherence to PEP and to minimize the risk of HIV seroconversion. This study also indicated the need for providers to be trained on the importance of HIV PEP, counseling, follow-up, and proper documentation of cases of child sexual abuse. The Ministry of Health should put in place effective commodity supply mechanisms to prevent stock-out of essential commodities such as PEP. In addition to training providers on delivery of pediatric HIV services, there exists a need for providers to be equipped with counseling-related skills to enable them to better meet the psychological needs of sexually abused children as well as their caregivers.

\section{Acknowledgments}

Special recognition goes to the health managers and health providers from the two hospitals in Nyeri and Naivasha County for their invaluable support throughout the study period. Recognition goes to the research assistants and all the participants who took part in this study. We acknowledge the oversight received from Dr Chi Chi Undie of the Population Council, Nairobi. Special thanks go to the SwedishNorwegian Regional HIV and AIDS Team for Africa, through the Population Council for financing this study.

\section{Author contributions}

All authors contributed toward data analysis, drafting and revising the paper and agree to be accountable for all aspects of the work.

\section{Disclosure}

The authors report no conflicts of interest in this work.

\section{References}

1. Murray LK, Nguyen A, Cohen JA. Child sexual abuse. Child Adolesc Psychiatr Clin NAm. 2014;23(2):321-337.

2. Pinheiro PS. World Report on Violence Against Children: United Nations Secretary-General's Study On Violence Against Children. Geneva: United Nations Publishing Services; 2006.

3. World Health Organization. Global Estimates of Health Consequences Due to Violence Against Children. Geneva: WHO; 2006.

4. Idele P, Gillespie A, Porth T, et al. Epidemiology of HIV and AIDS among adolescents: current status, inequities, and data gaps. J Acquir Immune Defic Syndr. 2014;66(Supp1 2):S144-S153.

5. Joint United Nations Programme on HIV/AIDS (UNAIDS). The Gap Report. Geneva: UNAIDS; 2014.

6. Meel BL. Incidence of HIV infection at the time of incident reporting, in victims of sexual assault, between 2000 and 2004, in Transkei, Eastern Cape, South Africa. Afr Health Sci. 2005;5(3):207-212.

7. Leiderman IZ, Grimm KT. A child with HIV infection. JAMA. 1986;256(22):3094. 
8. Markowitz SM, O'Cleirigh C, Hendriksen ES, Bullis JR, Stein M, Safren SA. Childhood sexual abuse and health risk behaviors in patients with HIV and a history of injection drug use. AIDS Behav. 2011;15(7):1554-1560.

9. Fang L, Chuang DM, Lee Y. Adverse childhood experiences, gender, and HIV risk behaviors: results from a population-based sample. Prev Med Rep. 2016;4:113-120.

10. United Nations Children's Fund Kenya Country Office, Division of Violence Prevention, National Center for Injury Prevention and Control, U.S. Centers for Disease Control and Prevention, Kenya National Bureau of Statistics. Violence Against Children in Kenya: Findings from a 2010 National Survey. Summary Report on the Prevalence of Sexual, Physical and Emotional Violence, Context of Sexual Violence, and Health and Behavioral Consequences of Violence Experienced in Childhood. Nairobi: UNICEF; 2012.

11. Richter L, Komárek A, Desmond C, et al. Reported physical and sexual abuse in childhood and adult HIV risk behaviour in three African countries: findings from project accept (HPTN-043). AIDS Behav 2014;18(2):381-389.

12. Parillo KM, Freeman RC, Collier K, Young P. Association between early sexual abuse and adult HIV-risky sexual behaviors among communityrecruited women. Child Abuse Negl. 2001;25(3):335-346.

13. Paul JP, Catania J, Pollack L, Stall R. Understanding childhood sexual abuse as a predictor of sexual risk-taking among men who have sex with men: the Urban Men's Health Study. Child Abuse Negl. 2001;25(4):557-584.

14. Briere J, Elliott DM. Prevalence and psychological sequelae of selfreported childhood physical and sexual abuse in a general population sample of men and women. Child Abuse Negl. 2003;27(10):1205-1222.

15. Steel JL, Herlitz CA. The association between childhood and adolescent sexual abuse and proxies for sexual risk behavior: A random sample of the general population of Sweden. Child Abuse Negl. 2005;29(10):1141-1153.

16. Fergusson DM, Horwood LJ, Lynskey MT. Childhood sexual abuse, adolescent sexual behaviors and sexual revictimization. Child Abuse Negl. 1997;21(8): 789-803.

17. Collin-Vézina D, Daigneault I, Hébert M. Lessons learned from child sexual abuse research: prevalence, outcomes, and preventive strategies. Child Adolesc Psychiatry Ment Health. 2013;7(1):22.

18. Davis L, Siegel LJ. Posttraumatic stress disorder in children and adolescents: a review and analysis. Clin Child Fam Psychol Rev, 2000;3(3):135-154.
19. Holzemer WL, Corless IB, Nokes KM, et al. Predictors of self-reported adherence in persons living with HIV disease. AIDS Patient Care STDs. 1999;13(3):185-197.

20. Willie TC, Overstreet NM, Sullivan TP, Sikkema KJ, Hansen NB. Barriers to HIV medication adherence: examining distinct anxiety and depression symptoms among women living with HIV who experienced childhood sexual abuse. Behav Med. 2016;42(2):120-127.

21. Markowitz SM, O’Cleirigh C, Hendriksen ES, Bullis JR, Stein M, Safren SA. Childhood sexual abuse and health risk behaviors in patients with HIV and a history of injection drug use. AIDS Behav. 2011;15(7):1554-1560.

22. Mugavero MJ, Pence BW, Whetten K, et al. Childhood abuse and initial presentation for HIV care: an opportunity for early intervention. AIDS Care. 2007;19(9):1083-1087.

23. Ministry of Health - Government of Kenya. National Guidelines on Management of Sexual Violence in Kenya. Nairobi; 2014.

24. World Health Organization. Consolidated guidelines On The Use of Antiretroviral Drugs For Treating and Preventing HIV Infection: Recommendations for A Public Health Approach. Geneva: WHO; 2016.

25. Katz MH, Gerberding JL. Postexposure treatment of people exposed to the human immunodeficiency virus through sexual contact or injectiondrug use. New Engl J Med. 1997;336(15):1097-1100.

26. Sultan B, Benn P, Waters L. Current perspectives in HIV post-exposure prophylaxis. HIV/AIDS (Auckland, N.Z.). 2014;6:147-158.

27. Lurie P, Miller S, Hecht F, Chesney M, Lo B. Postexposure prophylaxis after nonoccupational HIV exposure: clinical, ethical, and policy considerations. JAMA. 1998;280(20):1769-1773.

28. Du Mont J, Macdonald S, Myhr T, Loutfy MR. Sustainability of an HIV PEP program for sexual assault survivors:"lessons learned" from health care providers. Open AIDS J. 2011;5:102-112.

29. Tetteh RA, Nartey ET, Lartey M, et al. Adverse events and adherence to HIV post-exposure prophylaxis: a cohort study at the Korle-Bu Teaching Hospital in Accra, Ghana. BMC Public Health. 2015;15:573.

30. Miller RJ, Cairns JS, Bridges S, Sarver N. Human immunodeficiency virus and AIDS: insights from animal lentiviruses. J Virol. 2000;74(16):7187-7195.

31. Havens PL; American Academy of Pediatrics Committee on Pediatric AIDS. Postexposure prophylaxis in children and adolescents for nonoccupational exposure to human immunodeficiency virus. Pediatrics. 2003;111(6 Pt 1):1475-1489.
Adolescent Health, Medicine and Therapeutics

\section{Publish your work in this journal}

Adolescent Health, Medicine and Therapeutics is an international, peer-reviewed, open access journal focusing on health, pathology, and treatment issues specific to the adolescent age group. All aspects of health maintenance, preventative measures and disease treatment interventions are addressed within the journal and practitioners from all disciplines are

\section{Dovepress}

invited to submit their work as well as healthcare researchers and patient support groups. This journal is included in PubMed. The manuscript management system is completely online and includes a very quick and fair peer-review system. Visit http://www.dovepress.com/testimonials. php to read real quotes from published authors. 